\title{
Dynamics of earthworm species at different depths of orchard soil receiving organic or chemical fertilizer amendments
}

\author{
Mojtaba Yahyaabadi, Amir Hossein Hamidian*, Sohrab Ashrafi
}

Department of Environmental Science and Engineering, Faculty of Natural Resources, University of Tehran, Karaj, Iran

\begin{abstract}
We investigated the dynamics of different earthworm species through the soil profile, which had received short-term amendments of either organic or inorganic fertilizer in an orchard during the spring of 2016. Earthworm populations were sampled at two consecutive depths of soil on 20 and 60 days after addition of fertilizers. The dominant earthworm species were Eisenia fetida (Savigny, 1826), Dendrobaena veneta (Rosa, 1886), Dendrobaena hortensis (Michaelsen, 1890), Lumbricus terrestris (Linnaeus, 1758) and Aporrectodea longa (Ude, 1885). Seven different types of fertilizers including Urea, Ammonium sulfate (AS), Diammonium phosphate (DAP), Solupotas, NPK (15-5-25), $(\mathrm{NPK}+\mathrm{OM})$ and organic manure $(\mathrm{OM})$ as experimental treatments were studied. Fluctuations in earthworm numbers and biomass were attributed to changes in time and depth of sampling, in addition to the types of fertilizers. The results of the means comparison showed that on the 20 th day, at $0-20 \mathrm{~cm}$ soil depth, E. fetida species abundance was decreased significantly in AS and Urea treatments compared to the control plot $(\mathrm{p}<0.05)$. We highlighted that from epigeic group, D. hortensis species had a better chance to survive and its population in AS treatment was more than that of Urea treatment. Results also showed that the anecic L. terrestris, had a greater tolerance to chemical fertilizers compared to the A. Longa species. The results of this study outline more clear horizons in managing the use of chemical fertilizers while simultaneously maintaining the biodiversity of soil organisms.
\end{abstract}

Keywords: Chemical fertilizer, organic fertilizer, earthworm species, abundance, biomass.

(C) 2018 Federation of Eurasian Soil Science Societies. All rights reserved

\section{Introduction}

The emphasis on increasing agricultural production has led to the addition of a wide variety of chemicals, pesticides and inorganic fertilizers to agricultural land. It is well known that earthworms influence nutrient cycling processes in terrestrial ecosystems significantly (Lee, 1985; Blair et al., 1995; Edwards and Bohlen, 1996), and as farm managers continue to move towards reduced input agriculture, earthworms could become even more important in affecting soil productivity and fertility in agroecosystems. Soil is a habitat supporting different forms of life and reservoir of all the agrochemicals. By entering the soil, these materials may disturb the soil ecosystems and undermine the physical, chemical and biological components, in particular, of non-target beneficial microorganisms and earthworms (Anderson, 1978; Edwards and Bohlen, 1992). Brown et al. (1999) showed significant increases in plant growth due to earthworm inoculation in $72 \%$ of the studied cases, with the effects varying with earthworm species and soil type. Because of their useful role in agro-ecosystems, earthworms are used as indicator species to monitor the impact of pollutants, changes in soil structure and agricultural practices (Eijsackers, 2004).

\footnotetext{
${ }^{*}$ Corresponding author.

Department of Environmental Science and Engineering, Faculty of Natural Resources, University of Tehran, Karaj, 31587-77871 Iran Tel.: +982632223044 E-mail address: a.hamidian@ut.ac.ir e-ISSN: 2147-4249 DOI: $10.18393 /$ ejss. 454506
} 
The number of earthworms in soil represents the health of the soil ecosystem and indicates environmental safety and a large population of earthworms is often recognized as a sign of a healthy soil (Romig et al., 1996). In light of the importance of earthworms in the dynamics of organic matter and soil structure, ecologists such as Hendrix et al. (1992); Edwards et al. (1995); and Ernst (2009) believe that long-term sustainability of agricultural soils could be improved by employing management practices that increase the number of earthworms. Several studies have been carried out on the toxic impact of some pesticides on soil organisms, especially earthworms, although little research has been done on the toxicity of different fertilizers on earthworms in a soil profile. A number of studies have found the positive effects of fertilizers on earthworms and their populations (Syers and Springett, 1984; Estevez et al., 1996; Curry et al., 2008). Few researchers also emphasized the negative effects of chemical fertilizers on earthworms (Marhan and Scheu, 2005; Bunemann et al., 2006; Tindaon et al., 2011; Bhattacharya and Sahu, 2014). Nearly all cultivated soils are treated with either organic or chemical fertilizers. The effects of these fertilizers on earthworms may be direct, for instance, by changing the acidity of soil or through toxicity (e.g. the ammonium radical), or indirect, by changing the form and quantity of the vegetation that ultimately turns into decaying organic matter that supplies food for earthworms. There is evidence that some inorganic nitrogenous fertilizers help the build-up of large numbers of earthworms, probably due to increased amounts of crop residues being returned to the soil (Lofs-Holmin, 1983). Rai et al. (2014) found a positive correlation between the mortality of Eisenia fetida and the concentration of urea fertilizer. Other studies showed that the application of fertilizers with nitrogen and phosphorous caused significant increases in earthworm number and biomass in an oxisoil (Iordache, and Borza, 2010). Whalen et al. (1998) concluded that the types of fertilization significantly influences the abundance and biomass of earthworms in corn fields. They demonstrated that earthworm numbers and biomass were significantly greater in manureamended plots compared to inorganic fertilizer treated plots during the majority of the study period, so that the population of Lumbricus spp in organic fertilization was $18.5 \%$ higher than mineral nitrogen fertilizer. It seems there have been no comprehensive research on response of earthworm to inorganic fertilizers at two consecutive depths of soil profile. Due to the importance of gardening in Iran, assessing the dynamics of earthworm communities in different depths of an orchard soil receiving amendments of organic or inorganic fertilizer is the main purpose of this paper.

\section{Material and Methods}

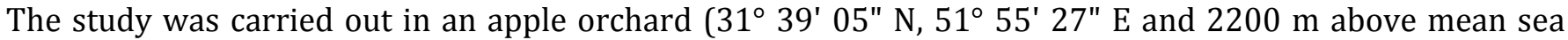
level), located in Esfarjan village in Isfahan Province, central Iran. The climate of the study area is BSk according to the agro-climatic classification of Koppen Geiger (Peel et al., 2007). Over the past 15 years, no inorganic fertilizer has been used in orchards of the target village. Compound soil samples from two depth of soil were taken to determine soil properties. The soil was classified as fine loamy, carbonatic, thermic, Typic Calcixerols with $27 \%$ silt, 25\% clay, and 48\% sand (Soil Survey Staff, 2010). Basic properties of the soil are given in Table 1. Earthworms were washed in fresh water and stored on the presence or absence of clitellum and clitellated earthworms were narcotized in 70\% ethyl alcohol, fixed in 5\% formalin for 6-8 h, and finally preserved in $5 \%$ formalin. The preserved samples were studied morphologically and dissected for study diagnostic taxonomic character such as spermathecae (number and location), prostate gland (location and shape), prostomium shape, and clitellum position. Finally, they were identified according to Sims and Gerard (1999) and Blakemore (2008). One square meter area of the soil surface with three replicates at a one-meter interval were considered as experimental plots. After plowing and grooving at depth of five centimeters per plot, common fertilizers, based on the soil test were applied. Chemical fertilizers such as Urea $(30 \mathrm{mg} / \mathrm{kg}$ soil), Ammonium sulfate (AS) (38 mg/kg soil), Diammonium phosphate (DAP) (19 mg/kg soil), Solupotas $(20 \mathrm{mg} / \mathrm{kg}$ soil), complete macro fertilizer containing nitrogen, phosphorus and potassium (NPK, 15-5-25) at a rate of $23 \mathrm{mg} / \mathrm{kg}$ of soil (NPK), the combination of decayed organic manure and complete macro fertilizer $(\mathrm{NPK}+\mathrm{OM})$ with the ratio of two to one including $15 \mathrm{mg} / \mathrm{kg}$ of soil NPK and decayed organic manure at 1.5 $\mathrm{g} / \mathrm{kg}$ of soil, decayed organic manure (OM) at a rate of four grams per kilogram of soil were used as experimental treatments together with control plot with no chemical or organic fertilizer (Control). During the experiment, soil moisture was maintained at the field capacity level (FC) and the surface of the test plots was covered with gunny bag. Abundance and live weight of worms were measured in two stages of time and in 2 depths of $0-20$ and $20-40 \mathrm{~cm}$ of soil profile. In the first stage, 20 days after addition of fertilizers, and in the second stage, 60 days after fertilization, earthworms were sampled by hand sorting method (Edwards and Bohlen, 1996) and their number were measured. The worms were also allowed to evacuate their digestive system on a filter paper and their live weight (biomass) was measured. Treatments were applied in 
three replications and data were transformed when necessary to improve homogeneity of variances using a square-root transformation (Zar, 1996). Untransformed data are presented in the figures. Meanwhile the data were analyzed using two-way ANOVA (using the GLM process) by SPSS software. In addition, means comparisons were tested with the least significant difference (LSD) at the probability level of 5\%. Variables (response traits) included in the analysis were earthworm biomass (expressed as g.m- ${ }^{2}$ ) and density (expressed as no.m- ${ }^{2}$ ).

Table 1. Chemical and physical properties of experiment soils

\begin{tabular}{cccccccccc}
\hline $\begin{array}{c}\text { Soil } \\
\text { texture }\end{array}$ & $\begin{array}{c}\mathrm{BD}, \\
\mathrm{g} \cdot \mathrm{cm}^{-3}\end{array}$ & $\begin{array}{c}\mathrm{K}, \\
\mathrm{mg} \cdot \mathrm{kg}^{-1}\end{array}$ & $\begin{array}{c}\mathrm{P}, \\
\mathrm{mg} \cdot \mathrm{kg}^{-1}\end{array}$ & $\begin{array}{c}\text { Total N, } \\
\%\end{array}$ & $\begin{array}{c}\text { OC, } \\
\%\end{array}$ & $\begin{array}{c}\mathrm{CaCO}_{3}, \\
\%\end{array}$ & $\begin{array}{c}\mathrm{EC}, \\
\mathrm{dSm}^{-1}\end{array}$ & $\begin{array}{c}\mathrm{pH} \\
\text { Soil depth, } \\
\mathrm{cm}^{2}\end{array}$ \\
\hline SL & 1.42 & 185 & 19.5 & 0.14 & 1.2 & 24 & 0.5 & 7.0 & $0-20$ \\
SL & 1.47 & 192 & 17.7 & 0.14 & 1.2 & 26 & 0.5 & 7.1 & $20-40$ \\
\hline
\end{tabular}

\section{Results and Discussion}

The results of means comparisons are given in details at two stages of time and two soil depths.

\section{$20^{\text {th }}$ day, depth of $0-20 \mathrm{~cm}$}

In shallow depths of soil $(0-20 \mathrm{~cm})$, the highest number of worms in the control plots belonged to $D$. veneta and E. fetida of epigeic ecological group and L. terrestris species of anecic ecological group respectively. The results of the mean comparison showed that on $20^{\text {th }}$ day and in the depth of $0-20 \mathrm{~cm}, E$. fetida species decreased significantly in AS and Urea treatments compared to the control plot $(\mathrm{p}<0.05)$. ) Hendrix et al. (1992) showed that the use of nitrogenous fertilizers could reduce the number of worms in the soil. Other researchers found similar results for the Enchytraeidae worms (Zajonc, 1975). However, Edwards and Lofti (1982) reported that there is a positive correlation between the amount of inorganic nitrogen and the number of worms in agricultural soils. They also concluded that the effect of organic fertilizers on the populations of L. terrestris was higher than Allolobofora longa, A. caliginosa and A. chorotica. NPK+OM treatment significantly increased the number of E. fetida species compared to the control. Comparison of the effect of two nitrogen supplier fertilizers (AS and Urea) showed that D. hortensis species had a better chances to survive and its population in AS treatment was more than that of Urea treatment. The relatively high numbers of D. veneta compared to the E. fetida in Urea and AS treatment are hard to explain, but might be related to the differences of physiology and biology of these earthworms species. The remaining species did not reveal any significant statistical differences in these two treatments (Figure 1A). No significant differences were observed between different species abundance of the two phosphorus compounds, DAP, NPK. Although, the combination of NPK+OM showed a significant increase in the population of both epigeic E. fetida and D.veneta compared to DAP and NPK treatments and it confirms the indisputable role of organic fertilizers in this regard. Curry (2004) and Jordan et al. (2004) reported that addition of farmyard manures and animal slurries increased earthworm populations rapidly. However, some liquid organic manures that have not been aged or composted can have short-term adverse effects on earthworm populations (Curry, 1976), due to their ammonia and salt contents. Timmerman et al. (2006) found that earthworm numbers in no fertilization treatment were higher than in the slurry manure treatment. This is in contrast with the general observation that earthworm abundance is higher under fertilized conditions. It was not unexpected that OM treatment alone had the same effect. It seems that chemical fertilizers had the most negative effect on the earthworms living in this depth of soil and time of sampling; meanwhile, using organic fertilizers reduces their harmful impact on earthworms. In case of biomass, a similar trend was also observed with earthworm populations. The results indicated a significant negative reaction of L. terrestris biomass to AS and DAP treatments compared to the control. Simultaneously, E. fetida and L. terrestris species in NPK + OM plots, encountered a significant increase in biomass compared to the control and the biomass of A. longa was increased in the OM treatment compared to the control plot (Figure 1B). The comparison of Urea and AS fertilizers showed that L.terrestris species have more biomass in Urea than AS treatment $(\mathrm{p}<0.05)$. The results in this section of the experiment showed that the anecic $A$. longa had a higher biomass in the $\mathrm{NPK}+\mathrm{OM}$ treatment than in NPK because of organic compound (OM). Whilst, other species did not show any differences. Impacts of phosphate fertilizers on worms are also paradoxically reported, and these effects probably vary with the soil conditions. Gerard and Hey (1979) concluded that superphosphate decreased the number of earthworms in grass plots. Meanwhile, no significant effect was seen in earthworms biomass by fertilizer containing potassium (Solupotas). 

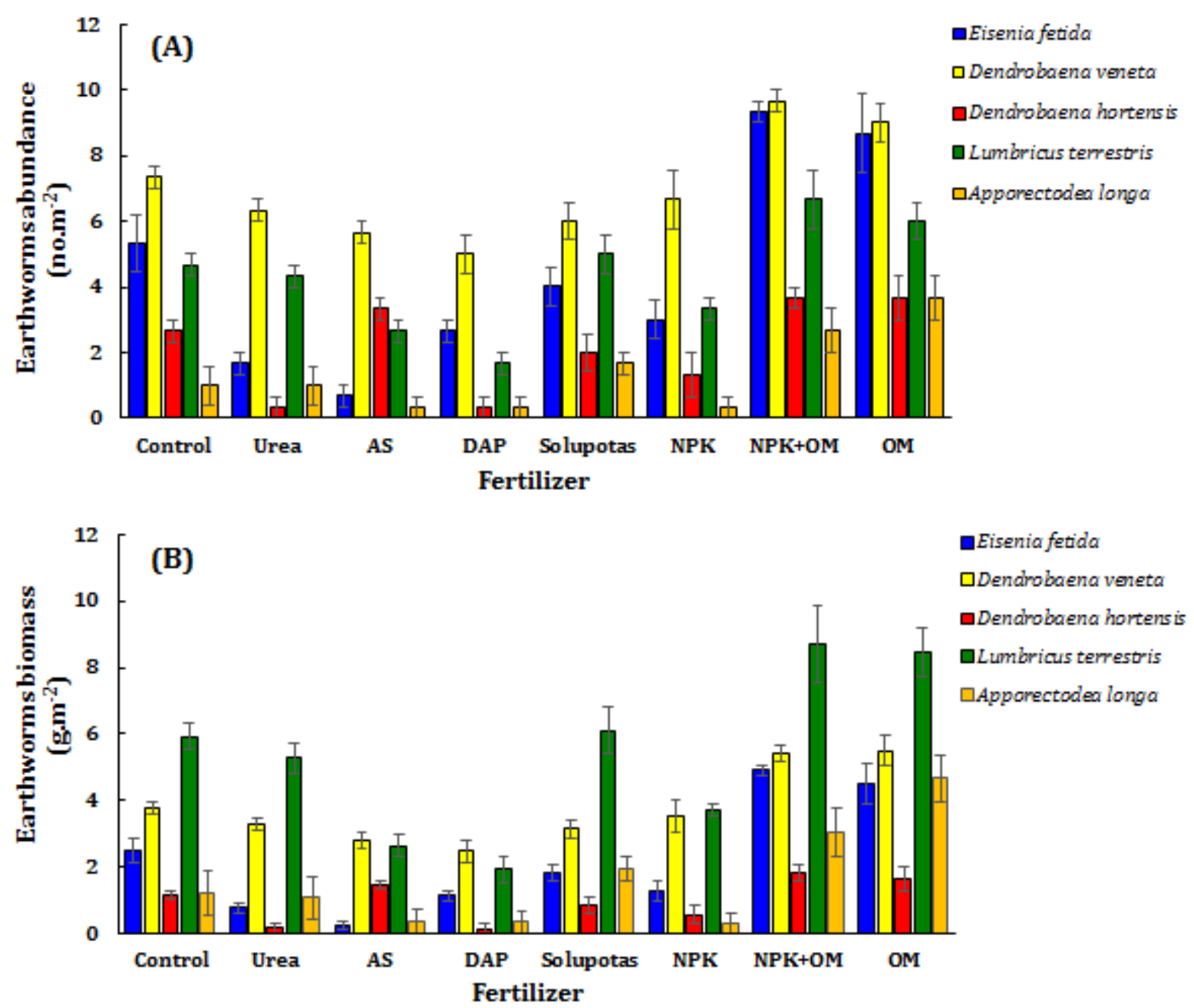

Figure 1. Means' comparisons of (A) earthworms species' abundance and (B) earthworms species' biomass in plots receiving different fertilizer amendments on 20 th day at depth of $0-20 \mathrm{~cm}$. $\mathrm{P}<0.05$ (LSD).

\section{$20^{\text {th }}$ day, depth of $20-40 \mathrm{~cm}$}

At lower depth, the highest number of worms belonged to L. terrestris and A. longa, respectively, and D. hortensis species recorded the lowest number. Comparison of means of earthworms species abundance showed that none of the fertilizer treatments could have a significant effect on earthworms species at 20-40 $\mathrm{cm}$ soil depth compared to control plots (Figure 2A). Earthworms seem to be less damaging from the negative effects of chemical fertilizers in deeper soil. The highest L. terrestris population was observed in Sulopotas containing plots, which showed a significant difference with the same species in AS treatment. From the point of view of earthworm biomass at depths of 20-40 cm, data clearly indicated that the most biomass content belonged to L. terrestris and A. longa as the same as worms population. Comparisons of earthworms species' biomass showed that fertilizer treatments did not have a statistically effect on earthworms as compared to the control plots (Figure 2B). We found that L. terrestris had grater biomass in Urea treatment than that in AS treatment $(\mathrm{p}<0.05)$. Moreover, DAP and NPK treatments did not differ significantly. Most of the biomass weights at depth of 20-40 cm belonged to L. terrestris species in OM treatment. Probably the influence of organic matter on all species is mainly through increasing their food supply, whether they feed directly on the organic matter or on microorganisms growing upon it. 

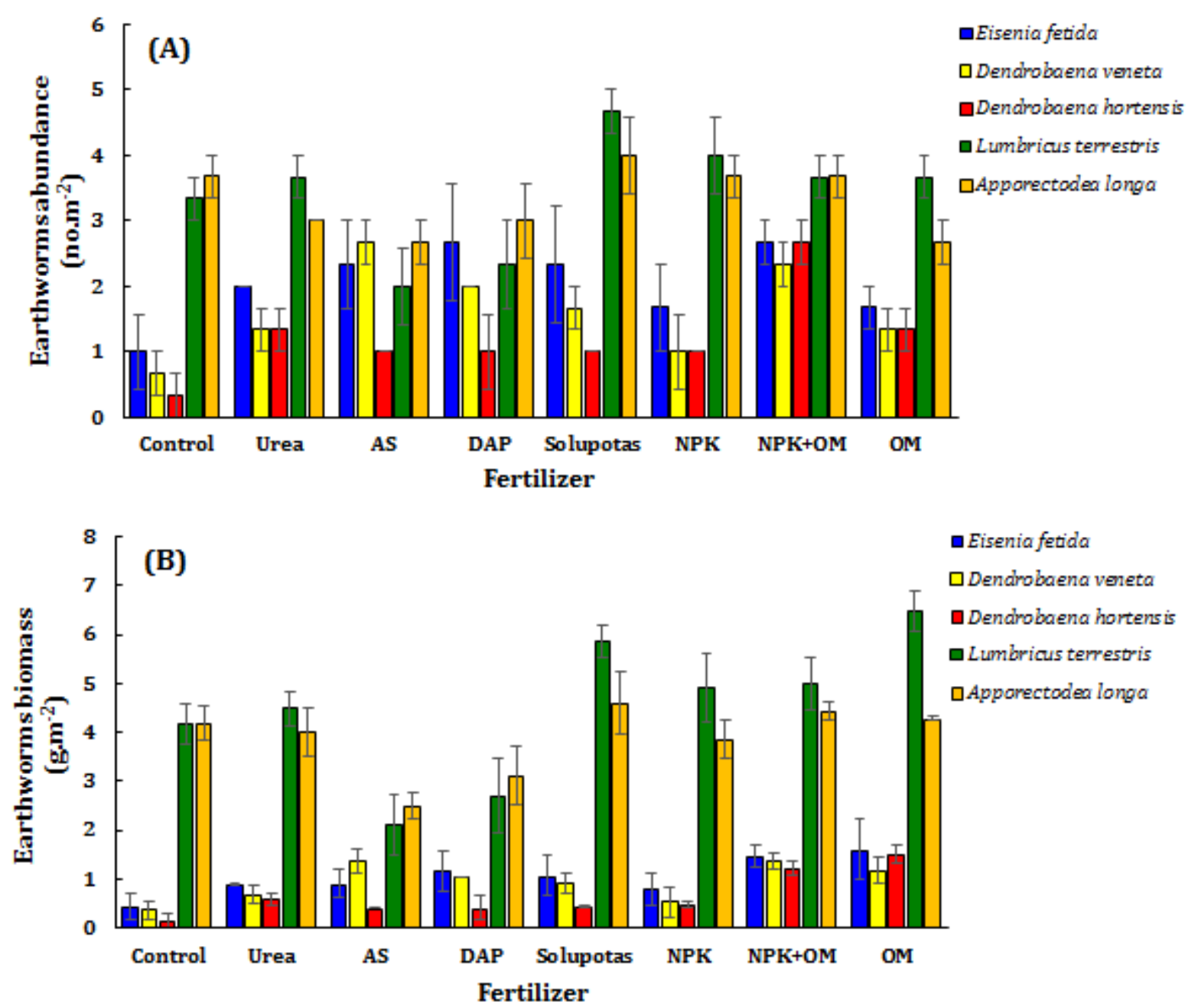

Figure 2. Means' comparisons of (A) earthworms species' abundance and (B) earthworms species' biomass in plots receiving different fertilizer amendments on 20 th day at depth of 20-40 cm. P<0.05 (LSD).

\section{$6^{\text {th }}$ day, depth of $0-20 \mathrm{~cm}$}

60 days after adding fertilizers, epigeic $D$. veneta and $E$. fetida were the most populous species and $A$. longa species was the least populous species at depth of 0-20 cm. Comparison of means by species showed that number of E. fetida species was decreased drastically in AS treatment compared to control plot (Figure 3A). Several authors have attempted to define that endogeic species of earthworms such as Aporrectodea spp. were more strongly affected than the epigeic group of Lumbricus spp., although an exception was noted for A. caliginosa tuberculata (Ma et al., 1990). At the same time, applying NPK+OM treatment significantly increased the number of D. veneta and E. fetida species compared to control. Meanwhile, the studied species did not indicate any significant difference in AS and urea treatments, however, number of E.fetida and D. veneta species in NPK+OM containing plots was more than in NPK containing plots. In most treatments, the population of $D$. veneta was more than other species, indicating the adaptation of this species to the environment. Measuring the biomass of different species at 0-20 cm depth showed that the highest biomass belonged to $L$. terrestris and D. veneta species. In NPK+OM treatment, the biomass of E. fetida increased significantly with respect to control treatment. Also, biomass of E. fetida species increased significantly in OM compared to similar species in control plot (Figure 3B). Guo et al. (2016), demonstrated that applying merely chemical fertilizers resulted in negative effects on earthworm activity, while cattle manure alleviated such negative effects, after applying cattle manure compost combined with chemical fertilizer to a wheatmaize rotation field. Unexpectedly, the five identified species did not show significant differences in AS and Urea treatments, which appeared that after 60 days, chemical conditions of the soil have reached a balance and earthworms have been able to withstand the initial stress. The presence of organic matter (OM) in experimental plots led to a significant increase in biomass of E. fetida, L. terrestris and A. longa than similar species in NPK treatment. The organic fertilizers probably act directly by providing food for the earthworms. This was most obvious for populations of L. terrestris, which increased more than those of other species did probably because it feeds directly on surface organic matter. 

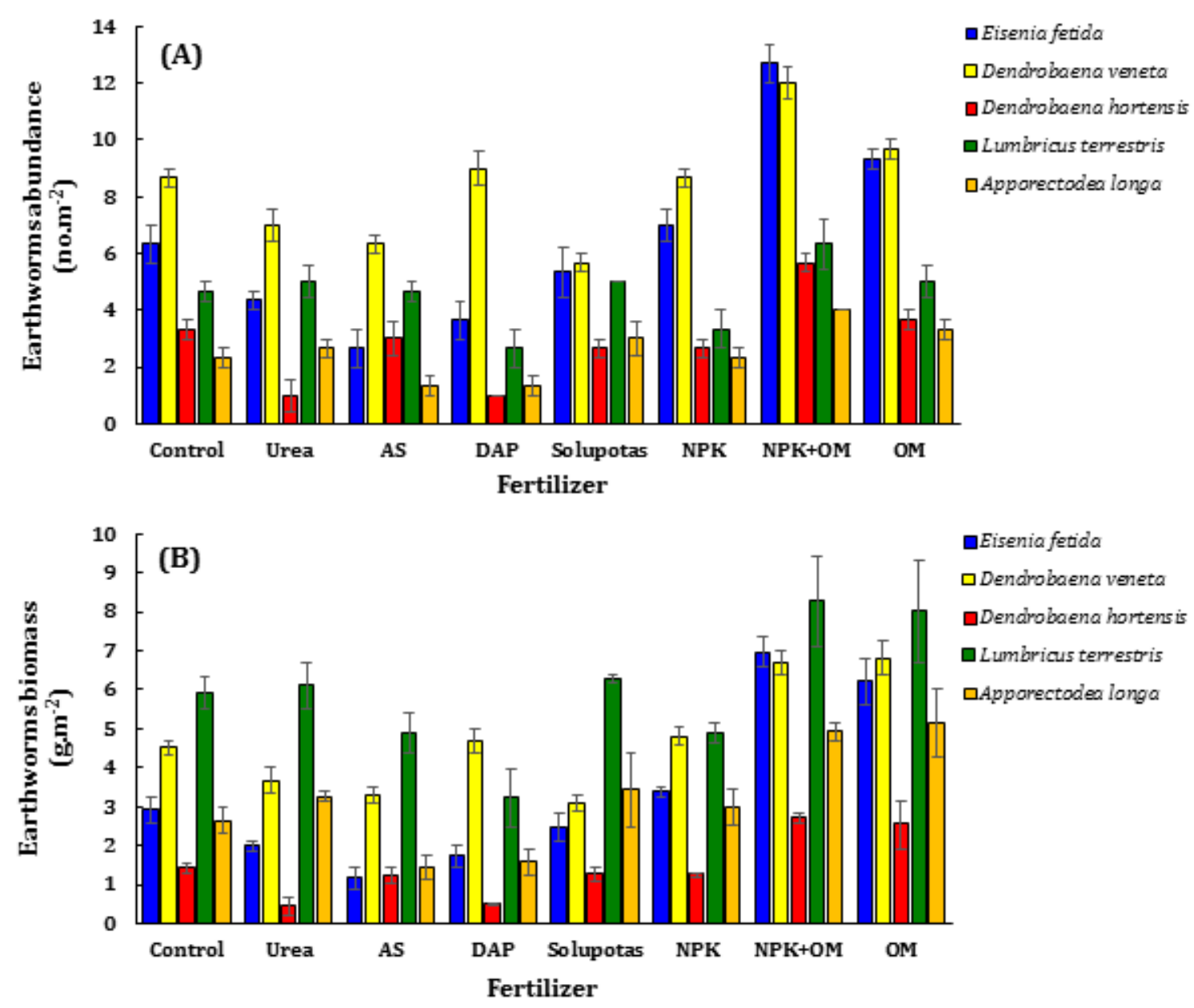

Figure 3. Means' comparisons of (A) earthworms species' abundance and (B) earthworms species' biomass in plots receiving different fertilizer amendments on 60 th day at depth of $0-20 \mathrm{~cm}$. $\mathrm{P}<0.05$ (LSD).

\section{$60^{\text {th }}$ day, depth of $20-40 \mathrm{~cm}$}

At depth of 20-40 cm, 60 days after adding fertilizers, the highest number of earthworms belonged to anecic $A$. longa and $L$. terrestris and the lowest number of earthworms referenced to epigeic $D$. hortensis and $E$. fetida (Figure 4A). Surprisingly the only significant change in worm populations was the increase in the number of $L$. terrestris species in plots containing AS and Urea treatments compared to the same species in control plot. It is less clear how these inorganic nitrogenous fertilizers favour the build-up of earthworm populations. It seems that 60 days after using of chemical fertilizers, these compounds have undergone chemical changes and their destructive effects have diminished. Moreover, the highest biomass in this depth was related to $A$. longa and L. terrestris species. Under those circumstances, the biomass of L. terrestris in all plots showed a significant increase $(\mathrm{p}<0.05)$ compared to the same species in the control plot (Figure 4B).

\section{Conclusion}

Results obtained in this study indicate that among the epigeic group of earthworms, $D$. Veneta had the most resistance or compatibility with chemical fertilizers and in anecic group; L. terrestris was able to withstand the condition of inorganic fertilizers. Yet, it is impossible to give a definitive and clear-cut recommendation on the effect of chemical fertilizers on earthworms. On the other hand, the effects of mineral fertilizer on earthworms are variable. Some inorganic fertilizers that are recommended by the soil test may be below the critical level for worms and found to be safe for them. However, there is higher possibility of having sublethal effect of these chemical amendments on earthworm. This is because; all the agrochemical go through bioaccumulation in the animal and plants tissues. It is also evident that the effects of various inorganic fertilizers on earthworms apparently vary from site to site and depth to depth as well. We concluded that ammonium sulfate caused a sharp reduction in the number of worms in the soil, especially in the depths of the surface of the soil. Epigeic earthworms are very sensitive in this regard because of their low drilling power. If it is necessary to use these fertilizers, it is advisable to use them in deep soil depth. It is also 
appropriate to use organic fertilizers along with inorganic fertilizers such as urea or NPK. The adverse influence of chemical fertilizers could be alleviated by application of organic and natural inputs. Our results confirm these findings and provide a basis for speculation on the ways in which inorganic fertilizers increase earthworm populations in deeper depth of soils regardless of types of these amendments.
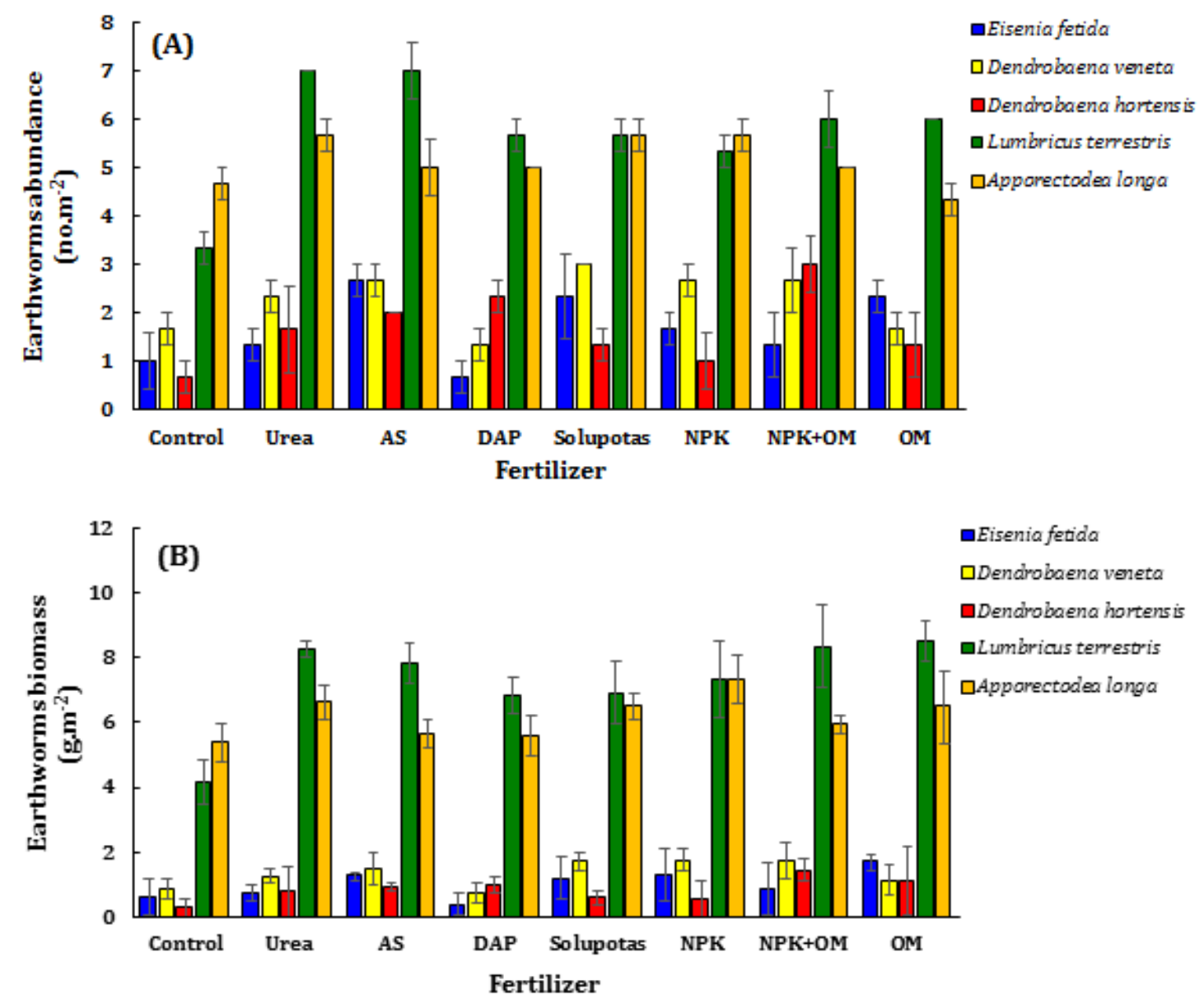

Figure 4. Means' comparisons of (A) earthworms species' abundance and (B) earthworms species' biomass in plots receiving different fertilizer amendments on 60th day at depth of $20-40 \mathrm{~cm} . \mathrm{P}<0.05$ (LSD).

\section{Acknowledgements}

The authors are grateful to Tehran University for the financial support, and Isfahan Agricultural and Natural Resources Research and Education Center for the lab support. Special appreciation is extended to Dr. M. Sabzalian of Department of Agronomy and Plant Breeding, Isfahan University of Technology for providing statistical support.

\section{References}

Anderson, JR., 1978. Pesticide effects on non-target soil microorganisms. In: Pesticides Microbiology, Hill, I.R., Wright, S.J.L. (Eds.). Academic Press, London, UK. pp. 313-33.

Bhattacharya, A., Sahu, SK., 2014. Lethal effect of urea on soil biota: a laboratory study on earthworm (Drawida willsi). Journal of Biodiversity and Environmental Sciences 4(6): 64-72.

Blair, J.M., Parmelee, R.W., Lavelle, P., 1995. Influences of earthworms on biogeochemistry. In: Hendrix, P.F. (Ed.), Earthworm Ecology and Biogeography in North America. Lewis Publishers, Boca Raton, USA. pp. 128-154.

Blakemore, R. J., 2008. Cosmopolitan Earthworms -an Eco-Taxonomic Guide to the Species. (3 ${ }^{\text {rd }}$ Edition). VermEcology, Yokohama, Japan. 757p.

Brown, G.G., Pashanasi, B., Villenave, C., Patron, J.C., Senapti, B.K., Giri, S., Barois, I., Lavelle, P., Blanchart, E., Blakemore, R.J., Spain, A.V., Boyer, J., 1999. Effects of earthworms on plant production in the tropics. In: Lavelle P., Brussaard, L., Hendrix, P. (Eds), Earthworm Management in Tropical agroecosystems. CABI Publishing, New York, USA. pp. 87-147.

Bunemann, E.K., Schwenke, G.D., Van Zwieten, L., 2006. Impacts of agricultural inputs on soil organisms - a review. Australian Journal of Soil Research 44(4): 379-406.

Curry, J.P., 1976. Some effects of animal manures on earthworms in grassland. Pedobiologica 16: 425-438. 
Curry, J.P., 2004. Factors affecting the abundance of earthworms in soils. In: Earthworm Ecology. Edwards, C.A. (Ed.), CRC press LLC, Boca Raton, Florida, USA. pp. 91-114.

Curry, J.P., Doherty, P., Purvis, G., Schmidt, O., 2008. Relationships between earthworm populations and management intensity in cattle-grazed pastures in Ireland. Applied Soil Ecology 39(1): 58-64.

Edwards, C.A., Bohlen, P.J., 1992. The effects of toxic chemicals on earthworms. Reviews of Environmental Contamination and Toxicology 125: 23-99.

Edwards, C.A., Bohlen, P.J., 1996. Biology and Ecology of Earthworms. Chapman \& Hall, London, UK. 426p.

Edwards, C.A., Bohlen, P.J., Linden, D.R., Subler, S., 1995. Earthworms and sustainable land use. In: Earthworm Ecology and Biogeography in North America. Hendrix, P.F. (Ed.), CRC Press, Boca Raton, Florida, USA. pp. 215-231.

Edwards, C.A., Lofty, J.R., 1982. Nitrogenous fertilizers and earthworm populations in agricultural soils. Soil Biology and Biochemistry 14(5): 515-521.

Eijsackers, H., 2004. Earthworms in environmental research. In: Earthworms Ecology, C.A. Edwards (Ed.), CRC Press, Boca Raton, Florida, USA. pp. 103-122.

Ernst, G., Emmerling, C., 2009. Impact of five different tillage systems on soil organic carbon content and the density, biomass and community composition of earthworms after a ten-year period. European Journal of Soil Biology 45(3): 247-251.

Estevez, B., N'Dayegamiye, A., Coderre, D., 1996. The effect on earthworm abundance and selected soil properties after 14 years of solid cattle manure and NPKMg fertilizer application. Canadian Journal of Soil Science 76(3): 351-355.

Gerard, B.M., Hay, R.K.M., 1979. The effect on earthworms of ploughing, tined cultivation, direct drilling and nitrogen in a barley monoculture system. The Journal of Agricultural Science 93(1): 147-155.

Guo, L., Wu, G., Li, Y., Li, C., Liu, W., Meng, J., Liu, H., Yu, X., Jiang, G., 2016. Effects of cattle manure compost combined with chemical fertilizer on topsoil organic matter, bulk density and earthworm activity in a wheat-maize rotation system in Eastern China. Soil and Tillage Research 156: 140-147.

Hendrix, P.F., Mueller, B.R., Bruce, R.R., Langdale, G.W., Parmelee, R.W., 1992. Abundance and distribution of earthworms in relation to landscape factors on the Georgia Piedmont, USA. Soil Biology and Biochemistry 24(12): 1357-1361.

Iordache, M., Borza, I., 2010. Relation between chemical indices of soil and earthworm abundance under chemical fertilization. Plant, Soil and Environment 56(9): 401-407.

Jordan, D., Miles, R.J., Hubbard, V.C., Lorenz, T., 2004. Effect of management practices and cropping systems on earthworm abundance and microbial activity in Sanborn Field: a 115-year-old agricultural field. Pedobiologia 48(2): 99-110.

Lee, K.E., 1985. Earthworms: Their ecology and relationships with soils and land use. Academic Press, Sydney, Australia. 411p.

Lofs-Holmin, A., 1983. Influence of agricultural practices on earthworms (Lumbricidae). Acta Agriculturae Scandinavica 33(3): 225-334.

Ma, W.C., Brussarrd, L., de Ridder, J.A., 1990. Long term effects of nitrogenous fertilizers on earthworms and their relation to soil acidification. Agriculture, Ecosystems \& Environment 30(1-2): 71-80.

Marhan, S., Scheu, S., 2005. The influence of mineral and organic fertilisers on the growth of the endogeic earthworm Octolasion tyrtaeum (Savigny). Pedobiologia 49(3): 239-249.

Peel, M.C., Finlayson, B.L., McMahon, T.A., 2007. Updated world map of the Koppen-Geiger climate classification. Hydrology and Earth System Sciences 11: 1633-1644.

Rai, N., Ashya, P., Rathore, D.S., 2014. Comparative study of the effect of chemical fertilizers and organic fertilizers on Eisenia foetida. International Journal of Innovative Research in Science Engineering and Technology 3(5): 1299112998.

Romig, D.E., Garlynd, M.J., Harris, R.F., 1996. Farmer-based assessment of soil quality: a soil health scorecard. In: Methods for Assessing Soil Quality. Doran, J.W., Jones, A.J. (Eds.), Soil Science Society of America, Madison, Wisconsin, USA. pp. 39-59.

Sims, R.W., Gerard, B.M., 1999. Earthworms: Notes for the Identification of British Species. Linnean Society of London and the Estuarine and Coastal Sciences Association, London, USA. pp. 169.

Soil Survey Staff, 2010. Keys to Soil Taxonomy, $11^{\text {th }}$ Edition. U.S. Department of Agriculture, USA. pp. 539-579.

Syers, J.K., Springett, J.A., 1984. Earthworms and soil fertility. Plant and Soil 76(1-3): 93-104.

Timmerman, A., Bos, D., Ouwehand, J., de Goede, R.G.M., 2006. Long-term effects of fertilisation regime on earthworm abundance in a semi-natural grassland area. Pedobiologia 50(5): 427-432.

Tindaon, F., Benckiser, G., Ottow, J.C.G., 2011. Side effects of nitrification inhibitors on non target microbial processes in soils. Journal of Tropical Soils 16(1): 7-16.

Whalen, J.K., Parmelee, R.W., Edwards C.A., 1998. Population dynamics of earthworm communities in corn agroecosystems receiving organic or inorganic fertilizer amendments. Biology and Fertility of Soils 27(4): 400407.

Zajonc, I., 1975. Variation in meadow associations of earthworms caused by the influence of nitrogen fertilizers and liquid manure irrigation. In: Proceedings $5^{\text {th }}$ Int. Colloquium in soil zoology, Prague, Czech Republic. pp. 497-503.

Zar, J.H., 1996. Biostatistical Analysis. $3^{\text {rd }}$ Edition, Prentice-Hall, Upper Saddle River, New Jersey, USA. 663p. 